\title{
Desarrollo de la comprensión lectora en estudiantes de educación primaria
}

\author{
Development of reading comprehension in elementary school students
}

Desenvolvimento da compreensão de leitura em alunos do ensino fundamental

\section{Riosely Carolina Condo Isla}

riocor8@gmail.com

https://orcid.org/0000-0001-6588-3148

Recibido: junio 2020

Revisado: julio 2020

Universidad Privada Domingo Savio, Potosí, Bolivia

\section{RESUMEN}

El propósito del documento fue presentar una propuesta educativa para atender las necesidades de comprensión lectora detectadas en los estudiantes de $1^{\circ \prime} A^{\prime \prime}$ de nivel de educación primaria. Metodológicamente se ubicó bajo un paradigma cualitativo, como una investigación proyectiva con un enfoque mixto para la recolección de los datos, el diseño es de campo. Las técnicas para la recolección de los datos fueron la observación no participativa, la entrevista y la encuesta y los instrumentos la guía de observación para la comprensión lectora de los estudiantes, la guía de entrevista, el cuestionario para los padres y el Test DIP (le) (Di Scala y Cantú, 2011) para el diagnóstico psicopedagógico para la lectura y escritura. Resultaron tres dimensiones de acuerdo al procesamiento de la información de la lectura de un texto: Recuperación, interpretación y valoración. Se concluyó constituyendo un discurso pedagógico desde creatividad, motivación y diversión en el proceso de comprensión lectora.

Palabras clave:

Comprensión lectora; educación primaria; propuesta educativa; estrategias para la lectura
ABSTRACT

The purpose of the document was to present an educational proposal to meet the reading comprehension needs detected in 1st " $A$ " students of primary education level. Methodologically, it was placed under a qualitative paradigm, as a projective research with a mixed approach for data collection, the design is field. The techniques for data collection were non-participatory observation, the interview and the survey and the instruments the observation guide for students' reading comprehension, the interview guide, the questionnaire for parents and the DIP Test (le ) (Di Scala and Cantú, 2011) for psychopedagogical diagnosis for reading and writing. Three dimensions were found according to the information processing of the reading of a text: Retrieval, interpretation and assessment. It was concluded by constituting a pedagogical discourse based on creativity, motivation and fun in the reading comprehension process.

Key words:

Reading comprehension; primary education; educational proposal; strategies for reading
RESUMO

O objetivo do documento foi apresentar uma proposta educacional para atender às necessidades de compreensão leitora detectadas em alunos da $1^{\text {a }}$ série " $A$ " do ensino fundamental. Metodologicamente, posicionouse sob um paradigma qualitativo, como uma pesquisa projetiva com abordagem mista de coleta de dados, o design é de campo. As técnicas de coleta de dados foram a observação não participante, a entrevista e o survey e os instrumentos o guia de observação para compreensão de leitura dos alunos, o guia de entrevista, o questionário para pais e o Teste DIP (le) (Di Scala e Cantú, 2011 ) para diagnóstico psicopedagógico para leitura e escrita. Três dimensões foram encontradas de acordo com o processamento da informação na leitura de um texto: recuperação, interpretação e avaliação. Concluiuse com a constituição de um discurso pedagógico pautado na criatividade, na motivação e na diversão no processo de compreensão leitora.

Palabras clave:

Comprensión lectora; educación primaria; propuesta educativa; estrategias para la lectur 


\section{INTRODUCCIÓN}

La adquisición de la lectura como habilidad no se reduce a la posibilidad de decodificar un conjunto de grafemas y pronunciarlos de manera correcta. Se trata también de comprender aquello que se lee, que el lector pueda extraer un significado de la lectura.

La comprensión lectora es un proceso complejo en el cual se construye e integra información que le permite al lector construir una representación coherente del texto dentro de su propio marco cognitivo y expectativas; para ello debe implicarse en un proceso de predicción e inferencia continua. (Martínez, Vidal-Abarca, Sellés, y Gilabert, 2008). Asimismo, Niño (2010) considera a la comprensión lectora como una "cualidad esencial del proceso de la lectura, orientándose a la interpretación, recuperación y valoración de la información o de los diversos manifiestos ocultos en los textos" (p.167).

Por la importancia que tiene en el desarrollo educativo del estudiante, la comprensión lectora es una variable con abundante evidencia empírica. Algunos autores como Bravo, (2000); González, (2005); Navarro (2005) y Cabell, Justice, Konold y McGinty (2011) coinciden en relacionarla con la adquisición de aprendizajes futuros y el éxito escolar de los estudiantes. Otros autores como Parodi (2010) y Baker, Smolkowski, Katz, Fien, Seeley, Kame'enui, y Beck (2008) establecen que los factores que intervienen en la adquisición de la comprensión lectora de los niños son: asistencia al preescolar, grado educativo de la madre y el padre, apoyo y modelado de los padres o algún adulto significativo en la familia que refuerce la lectura, la actitud del docente, las estrategias y métodos educativos utilizados, las características de los materiales o textos.

Al respecto Brunner y Elacqua (2003) distinguen entre contextos y señalan que en los países desarrollados, los logros de aprendizaje se atribuyen un $80 \%$ al factor estudiante/familia y $20 \%$ al factor escuela, en América Latina, es diferente, el factor estudiante/familia podría significar $60 \%$ por ciento y la escuela un $40 \%$. Estos datos nos permiten comprender la importancia de la escuela, de los educadores y psicopedagogos para proporcionar una enseñanza de calidad e impactar positivamente en el aprendizaje de los estudiantes.

Las características de las prácticas pedagógicas influyen de forma significativa en la velocidad y calidad de la adquisición y consolidación de la alfabetización de los estudiantes (Cuetos, 2008 y López, 2014). En este mismo orden de ideas Medina (2006) concluye que las prácticas pedagógicas pueden ser eficaces para neutralizar el efecto negativo de las condiciones socioculturales de estudiantes.

Lo antes planteado sustenta el desarrollo de estrategias metodológicas efectivas que permitan atender las carencias que tiene el niño cuando comienza su aprendizaje de la lectura y desarrollo de sus habilidades de comprensión lectora. Las características de las estrategias en esta investigación están fundamentadas en los principios psicológicos de relación concienciaconectividad, desarrollo de psiquis y unidad teoría práctica (Gervilla, 2006); los principios pedagógicos de enseñanza activa, repetitiva y cooperativa (Paymal, 2008) y desde la didáctica los principios de comunicación, actividad, creatividad (Díaz Barriga y Hernández, 2002). Asimismo se entiende la lectura como un proceso interactivo entre el lector, el texto y el contexto. El texto proporciona la información y el contexto contribuye con los factores físicos, sociales y psicológicos del ambiente socio educativo del lector (Medina, 2006).

Cabe resaltar que existe diferencia entre la enseñanza de la lectura y de la comprensión lectora, se hace más énfasis en la primera por lo cual el estudiante no posee las habilidades 
necesarias para comprender los textos (Defior, 1996). Tanto es así que el problema de comprender los textos prevalece hasta en los niveles superiores de educación, de allí radica la importancia de atender la comprensión lectora desde los primeros años de escuela primaria. El éxito para lograr un aprendizaje significativo de la lectura se afianza en las primeras etapas, puesto que el material impreso, la recreación de lo leído y el uso de métodos diferentes que logren motivar e interesar al niño a leer, predisponen al mismo a alcanzar niveles adecuados de comprensión.

A partir de una entrevista a la docente del $1^{\circ \prime} A$ " de nivel primaria de la Unidad Educativa "San Agustín de la Palca" se detectó su preocupación por las dificultades que presentan sus estudiantes para comprender lo que leen, cuando leen se saltan las palabras, otros deletrean las palabras que no conocen o se les dificulta, no recuerdan todo el texto y tampoco logran dar una opinión personal de la lectura realizada. Estos niños presentan problemas en la comprensión de la lectura, por tanto surge la necesidad de desarrollar las habilidades y destrezas para comprender lo leído, interpretar, asimilar los textos y adquirir nuevos conocimientos.

Se presenta de esta manera la pregunta de investigación ¿Cuáles son las características de una propuesta de estrategias educativas basada en fundamentos psicológicos, pedagógicos y didácticos que permita atender las necesidades en el desarrollo de las habilidades de comprensión lectora de los estudiantes de $1^{\circ} \mathrm{A} A$ " de nivel primaria de la Unidad Educativa "San Agustín de la Palca" en Potosí, Bolivia?

Objetivo: Diseñar una propuesta de estrategias educativas basada en fundamentos psicológicos, pedagógicos y didácticos que permita atender las necesidades en el desarrolla de las habilidades de comprensión lectora de los estudiantes de $1^{\circ \prime} A$ " de nivel primaria de la Unidad Educativa "San Agustín de la Palca" en Potosí, Bolivia.

\section{MÉTODO}

Fue una investigación proyectiva porque se diseñó una propuesta para responder a las necesidades diagnosticadas. El enfoque fue mixto, ya que se procesaron datos de forma cualitativa y cuantitativa. El diseño fue de campo, se recolectaron los datos en el contexto educativo natural. La población del estudio estuvo conformada por 27 sujetos, 13 estudiantes que cursan el $1^{\circ}$ " $A$ " de nivel primaria de la Unidad Educativa "San Agustín de la Palca", un docente y 13 padres de familia de los respectivos estudiantes.

Las técnicas para la recolección de los datos fueron la observación no participativa, la entrevista y la encuesta. Los instrumentos estuvieron conformados por la guía de observación para la actividad de comprensión lectora de los estudiantes, la cual se aplicó durante 6 días por 30 minutos para un total de 180 minutos de observación. La guía de entrevista dirigida a la docente y el cuestionario para los padres de familia. Otro instrumento fue el Test DIP (le) (Di Scala y Cantú, 2011) para el diagnóstico psicopedagógico para la lectura y escritura, sólo se reporta el resultado de los ítems de la comprensión lectora.

La variable dependiente fue la comprensión lectora, la cual queda operacionalizada con sus tres dimensiones de acuerdo al procesamiento de la información de la lectura de un texto: Recuperación, interpretación y valoración. (Ver Tabla 1). 
Tabla 1. Operacionalización de la variable dependiente.

\begin{tabular}{|c|c|c|c|c|c|c|}
\hline \multirow[b]{2}{*}{$\begin{array}{l}\text { Definición } \\
\text { Operativa }\end{array}$} & \multirow[b]{2}{*}{ Dimensiones } & \multirow[b]{2}{*}{ Indicadores } & \multicolumn{4}{|c|}{ Instrumentos } \\
\hline & & & $\begin{array}{l}\text { Observación } \\
\text { Niños }\end{array}$ & $\begin{array}{l}\text { Entrevista } \\
\text { Profesora }\end{array}$ & $\begin{array}{c}\text { Cuestionario } \\
\text { padres de } \\
\text { familia }\end{array}$ & $\begin{array}{l}\text { DIP (le) } \\
\text { Niños }\end{array}$ \\
\hline \multirow{8}{*}{$\begin{array}{l}\text { La lectura } \\
\text { comprensiva } \\
\text { es el proceso } \\
\text { mediante el } \\
\text { cual el lector } \\
\text { comprende, } \\
\text { se orienta, } \\
\text { recupera } \\
\text { ideas e } \\
\text { interpreta la } \\
\text { información } \\
\text { que aporta el } \\
\text { texto, en un } \\
\text { proceso que } \\
\text { permita } \\
\text { valorar y } \\
\text { darle sentido } \\
\text { al texto leído }\end{array}$} & \multirow[t]{3}{*}{$\begin{array}{l}\text { Recuperación } \\
\text { información }\end{array}$} & $\begin{array}{l}\text { Responde preguntas } \\
\text { relacionadas } \\
\text { a la lectura }\end{array}$ & Ítem: 1,2 & Preg. 1,2 & Preg. 1,2 & \\
\hline & & $\begin{array}{l}\text { Hace preguntas sobre } \\
\text { la lectura }\end{array}$ & Ítem: ,3, 4 & Preg. 2,4 & Preg. 2, 4 & \\
\hline & & $\begin{array}{l}\text { Recupera frases del } \\
\text { texto leído }\end{array}$ & Ítem: 5, & Preg. 5,6 & Preg. 5,6 & \\
\hline & \multirow[t]{2}{*}{$\begin{array}{l}\text { Interpretación } \\
\text { información }\end{array}$} & $\begin{array}{l}\text { Elabora resúmenes } \\
\text { o síntesis del texto } \\
\text { leído }\end{array}$ & Ítem: 6,7 & Preg. 7,8 & Preg. 7,8 & \\
\hline & & $\begin{array}{l}\text { Interpreta el texto a } \\
\text { partir de las imágenes }\end{array}$ & Ítem: 8,9 & Preg. $9,10,11$ & Preg. 9, 10,11 & \\
\hline & \multirow[t]{3}{*}{$\begin{array}{l}\text { Valoración } \\
\text { información }\end{array}$} & $\begin{array}{l}\text { Califica su posición } \\
\text { frente a la lectura }\end{array}$ & Ítem: 10,11 & Preg. 12, 13 & Preg. 12, 13 & \\
\hline & & $\begin{array}{l}\text { Evalúa la actitud de } \\
\text { los personajes }\end{array}$ & Ítem: 12, 13 & Preg. 14,15 & Preg. 14,15 & \\
\hline & & $\begin{array}{l}\text { Identificar cualidades } \\
\text { y defectos de los } \\
\text { personajes }\end{array}$ & Ítem: 14, 15 & Preg.16, 17 & Preg. 16, 17 & \\
\hline
\end{tabular}

\section{RESULTADOS}

Los resultados se presentan de acuerdo al instrumento utilizado.

La guía de observación permitió caracterizar el proceso de lectura comprensiva de los niños en el aula de clases desarrollando actividades de lectura con su docente. La guía de observación se clasificó en tres dimensiones de acuerdo al procesamiento de la información contenida en la lectura: (a) recuperación, (b) interpretación y (c) valoración.

Para describir la recuperación de la información se observa si los estudiantes logran identificar el mensaje central, recuerdan frases de la lectura, se adelantan a los acontecimientos de la historia, preguntan acerca de algún aspecto de la lectura y su capacidad para responder preguntas. Los resultados se resumen en el Gráfico 1. 


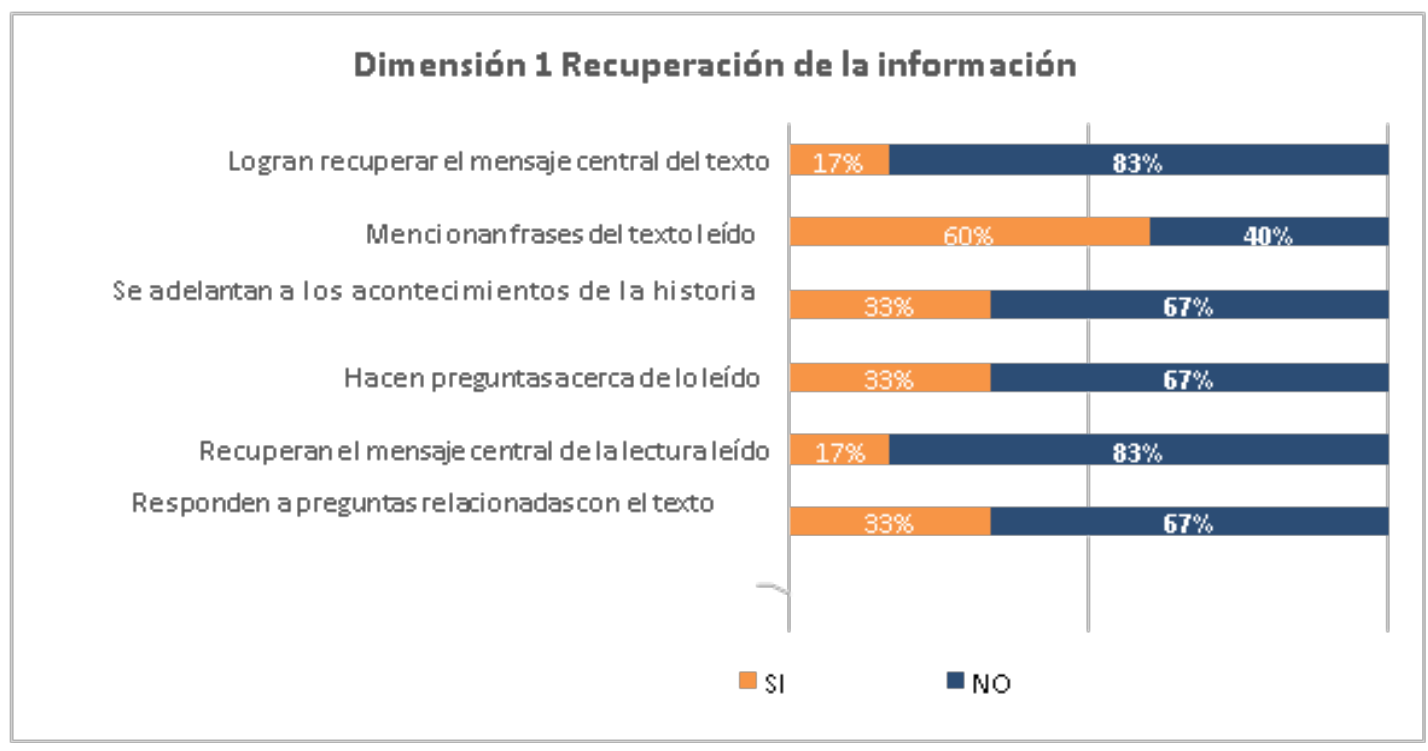

Gráfico 1. Dimensión 1 del proceso de comprensión lectora - Recuperación.

En la dimensión de la recuperación de la información el resultado fue positivo solo para la mención de pequeñas frases del texto leído, el $60 \%$ menciona frases el restante $40 \%$ no lo hace. El $83 \%$ de los estudiantes no logran recuperar el mensaje central del texto; el $67 \%$ no hacen ni responden preguntas acerca de la lectura y no son capaces de prever algún acontecimiento de la historia. Esto significa que los niños no recuperan la información del texto.

La dimensión 2 es la de interpretación de la información, los indicadores son la elaboración de resúmenes o síntesis y la caracterización de la historia a través de imágenes (Ver gráfico 2).

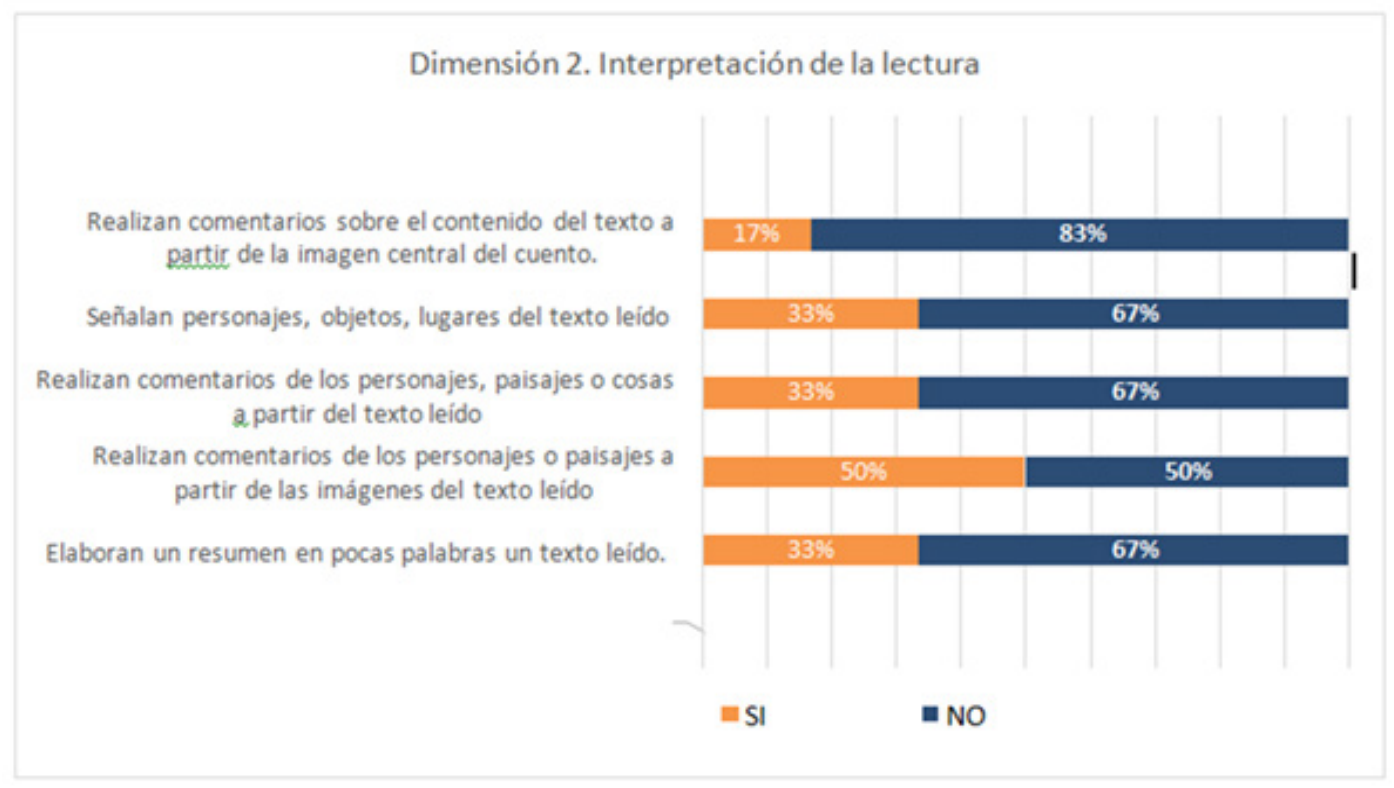

Gráfico 2. Dimensión 2 del proceso de comprensión lectora -Interpretación de la lectura. 
Solo el ítem, realizar comentarios de los personajes o paisajes, tiene resultados $50 \%$ Si y $50 \%$ No; en todos los demás predominó lo negativo. Esto significa que la mayoría de los niños tuvo dificultades para interpretar la lectura con base en las imágenes del texto y establecer la relación existente con su entorno.

El 67\% de los alumnos no tiene capacidad para elaborar resúmenes, realizar comentarios de los personajes o paisajes o señalar objetos personajes y lugares. Al mostrarles la imagen central del texto leído el $83 \%$ no realiza comentarios.

La dimensión 3 es la valoración de la lectura, tiene tres indicadores para calificar la posición ante a la lectura, evaluar la actitud de los personajes e identificar cualidades de los personajes, los resultados se pueden observar en el Gráfico 3.

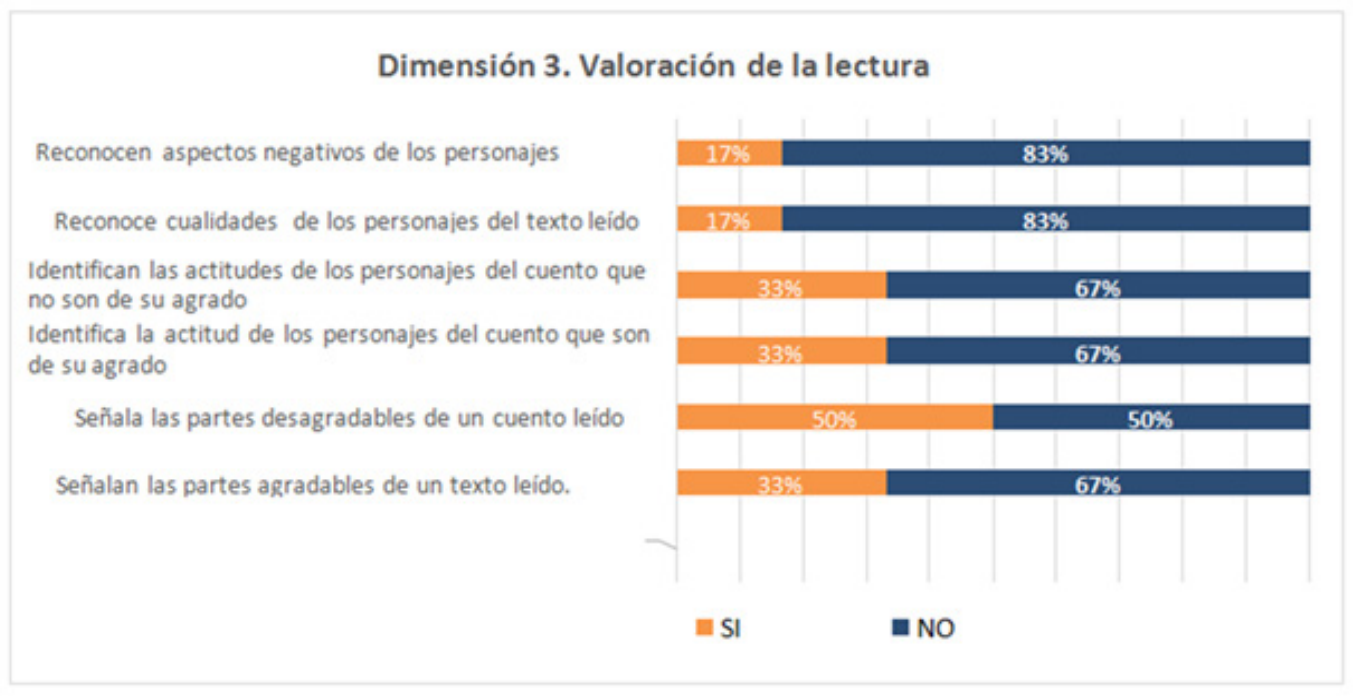

Gráfico 3. Dimensión del proceso de comprensión lectora - Valoración de la lectura.

El $83 \%$ de los alumnos no reconocen los aspectos negativos o positivos de los personajes; $67 \%$ no identifican actitudes de los personajes ni aspectos de la lectura agradables. El $50 \%$ señala las partes desagradables de la lectura. Esto significa que los niños no logran valorar la lectura leída entre los aspectos positivos y negativos, por lo que no comprenden lo que se les lee o leen a pesar que esos cuentos son sencillos y breves no logran comprender los textos.

\section{Guión de entrevista a la docente}

Este instrumento tuvo como objetivo caracterizar el proceso de lectura comprensiva de los niños en el aula de clases desarrollando actividades de lectura desde la perspectiva de la profesora. El guión de entrevista consta de tres dimensiones de acuerdo al procesamiento de la información contenida en la lectura: (a) recuperación, (b) interpretación y (c) valoración.

La recuperación de la información se les facilita a los estudiantes cuando se les lee el texto, se les dificulta cuando son ellos mismos quienes realizan la lectura. La docente declara que los niños muestran poco interés por la lectura.

La interpretación de la lectura mejora si se les muestra imágenes acerca de los paisajes o los personajes del cuento, si solo escuchan la 
lectura realizan muy pocos comentarios acerca de lo leído. Para las comprobaciones se les pide a los estudiantes que realicen cuentos cortos con aspectos de su entorno como la escuela, la bandera pero pocos son capaces de relacionar el contexto con la elaboración de un cuento.

La valoración de los personajes y situaciones del cuento solo dos estudiantes estuvieron en capacidad de realizarla, la mayoría no hace comentarios acerca de los aspectos negativos o positivos que contiene el texto leído.

\section{Cuestionario dirigido a los padres de familia}

Este instrumento tuvo como objetivo caracterizar el proceso de lectura comprensiva de los niños en el aula de clases desarrollando actividades de lectura desde la perspectiva de los padres de familia, considerando la lectura que realizan con sus hijos. El cuestionario consta de tres dimensiones de acuerdo al procesamiento de la información contenida en la lectura: (a) recuperación, (b) interpretación y (c) valoración.

Los resultados están de acuerdo con los obtenidos con la observación directa a los estudiantes y con la percepción de la docente.

La recuperación de la información es baja y los hijos o hijas muestran poco interés por realizar lecturas o por escucharlas., asimismo no logran recuperar la información de lo que leen, no identifican ideas y sensaciones que les permita tener una lectura comprensiva.

La dimensión interpretación tiene las mismas características resultantes de los otros instrumentos; a los niños se les dificulta interpretar la lectura realizada, por lo que no llegan a tener una lectura comprensiva, otro de los factores evidenciados en una de las pregunta, es que los niños nunca comentan algún tipo de libro que les guste. Por su edad los estudiantes de este nivel deberían realizar pequeños resúmenes del cuento sin demostrar muchas complicaciones y demostrar interés por diferentes tipos de lecturas como cuentos infantiles, historias, crónicas, fábulas entre otros.

En la dimensión valoración tanto niños como niñas presentan dificultades para valorar, en la lectura, entre lo bueno y lo malo, esto indica bajo nivel de comprensión.

Test DIP (le) (Di Scala y Cantú, 2011) Este es una prueba psicopedagógica para evaluar la lectura y escritura de los niños de primer nivel. Para esta investigación solo se utilizó lo referente a la lectura. El test posee tres niveles de evaluación, acerca de la comprensión lectora de los estudiantes (a) lectura realizada por el profesional que realiza el test, (b) lectura en voz alta realizada por el estudiante y (c) lectura silenciosa.

En el primer nivel que corresponde a la lectura realizada por el entrevistador, el $69 \%$ de los estudiantes tienen un desempeño negativo, no son capaces de retener lo que se les lee por lo tanto no logran responder a las preguntas realizadas acerca del cuento leído. Lo esperado es que los niños de primero de primaria según las teorías de la lectura comprensiva ya deben ser capaces de interpretar, recordar los cuentos que se les narra, lograr responder a las preguntas que se les hace con respecto a lo leído con o sin la ayuda del profesor.

En la segunda evaluación que es la lectura en voz alta el $62 \%$ de los niños no logran relacionar el dibujo con la palabra leída o la palabra con la imagen ni relacionar las imágenes con las oraciones. De acuerdo al fundamento teórico los niños entre 6 a 7 años de edad deben ser capaces de relacionar lo que leen con las imágenes del cuento, leer en voz alta pequeñas oraciones, frases y responder las preguntas acerca de la lectura realizada.

En la última prueba que es lectura silenciosa el $100 \%$ de los niños lograron obtener resultados positivos, por lo que identificaron la figura 
con la palabra y las oraciones con la figura correspondiente y lograron responder a las preguntas del cuento que leyeron en silencio. Esto concuerda con los resultados esperados para los niños de nivel primario, que deben ser capaces relacionar las imágenes con las palabras, comprender la secuencia de un cuento y responder a las preguntas planteadas del cuento que leen.

\section{Triangulación de resultados}

A continuación se presenta la triangulación de los resultados obtenidos para el diagnóstico de la comprensión lectora.

En la dimensión recuperación de la información, los niños presentan dificultades para Interpretar y recuperar el mensaje que contiene el cuento y no logran reconocer las partes más interesantes o sobresalientes del cuento leído. La valoración de la información es la más afectada. Otra de las dimensiones que se encuentran afectadas es la de interpretar la lectura los niños tienen grandes dificultades al señalar a los personajes, objetos lugares del cuento y no logran realizar un resumen en pocas palabras de todo lo que entendieron del cuento.

Todos los resultados obtenidos de los diferentes instrumentos fueron corroborados con la aplicación de la batería DIP (le), donde se pudo evidenciar que los niños si tienen diferentes problemas en la lectura comprensiva de textos, mostrando dificultades en extraer o interpretar el significado de un texto leído, identificar las diferentes palabras y oraciones con las imágenes, no logran identificar los diferentes hechos ocurridos en el cuento y de los personaje existentes del cuento ya que no logran responder a las preguntas planteadas de la lectura realizada.

Con base en estos resultados se diseña la propuesta para atender las dificultades de la comprensión lectora en la población sujeto de estudio en esta investigación.

\section{Propuesta estrategia didáctica para la comprensión lectora}

\section{Justificación}

Se fundamenta en varios principios, el principio de la relación conciencia - actividad (Gervilla, (2006). El proceso de interacción es la principal fuente de desarrollo de la conciencia mediante la realización de las actividades que generen la participación activa y creadora de los alumnos, esto además permite formar alumnos solidarios y cooperativos y desarrollar la inteligencia. Otro principio es el desarrollo de la psiquis, el desarrollo y evolución del cerebro del ser humano que atraviesa un desarrollo complejo, pero este desarrollo no es suficiente si no que es necesaria la estimulación que consistirá en las relaciones sociales, la inserción y en el proceso de aprendizaje. El principio de la unidad teóricapráctica consiste en que la teoría nunca se debe apartada de la práctica, ya que entre ambas hay un proceso de interacción, para el logro del aprendizaje significativo.

Paymal (2008) agrega los principios de la enseñanza activa, repetitiva y cooperativa. Estos principios se consideran para la elaboración de la estrategia didáctica.

\section{Objetivos}

- Desarrollar la comprensión lectora de los niños del primer nivel de escuela primaria de la Unidad Educativa San Agustín de la Palca ubicada en el área rural de la ciudad de Potosí.

- Promover el reconocimiento de características físicas y psicológicas de los personajes de un texto.

- Proporcionar herramientas para la elaboración de resúmenes con la secuencia de los hechos presentados en un texto.

- Generar competencias para comentar imágenes relacionadas con el texto de una lectura. 


\section{Actividades}

El taller educativo y el rincón de aprendizaje.

\section{Perfil del facilitador}

Profesional delapsicopedagogía con formación en desarrollo de procesos de comprensión lectora.

\section{Contenido}

Descripción de las características de los personajes, reconocimiento de aspectos positivos y negativos de los personajes, identificación de personajes, objetos y ambientes o contextos, elaboración de resúmenes, identificar el tema central, elaboración de secuencia de hechos utilizando imágenes, emite opiniones acerca del texto, lectura en voz alta y silenciosa.

\section{Planificación}

Nombre del taller: "La luz de la lectura comprensiva 1".

Objetivo. Identificar los personajes de un cuento.

\begin{tabular}{|c|c|c|c|}
\hline Etapas & Actividades & Materiales & Duración \\
\hline Inicio & $\begin{array}{l}\text { Pasar el globo } \\
\text { Sentados en círculo docentes y estudiantes. Comienza } \\
\text { el docente diciendo su nombre y pasando el globo al } \\
\text { que tiene a su derecha, así todos hasta completar el } \\
\text { círculo. A partir de ese momento quien tiene el globo se } \\
\text { lo debe lanzar a cualquier compañero diciendo primero } \\
\text { su nombre. La dinámica debe ser rápida procurando que } \\
\text { todos los alumnos reciban el globo más de una vez. }\end{array}$ & Globo & $5^{\prime}$ \\
\hline \multirow[t]{2}{*}{ Desarrollo } & $\begin{array}{l}\text { Sentados en círculo el facilitador presenta el cuento que } \\
\text { va a leer, le pide a los niños que presten atención. Realiza } \\
\text { la lectura. Basada en la temática del cuento el facilitador } \\
\text { les proporciona una caja con diversos materiales y les } \\
\text { pide a los niños que escojan materiales para representar } \\
\text { algún personaje del cuento. }\end{array}$ & $\begin{array}{l}\text { Caja de cartón } \\
\text { Máscaras } \\
\text { Disfraces } \\
\text { Capas } \\
\text { Sombrero } \\
\text { Lápices de cejas }\end{array}$ & $20^{\prime}$ \\
\hline & $\begin{array}{l}\text { Cada niño da una característica del personaje o habla } \\
\text { acerca de lo que hizo el personaje en el cuento. También } \\
\text { pueden dramatizar todo el cuento. }\end{array}$ & & \\
\hline \multirow[t]{2}{*}{$\begin{array}{l}\text { Cierre } \\
\text { evaluativo }\end{array}$} & $\begin{array}{l}\text { Se sientan todos en círculo y el facilitador hace diferentes } \\
\text { preguntas a los niños: ¿Quién puede hacer un resumen de } \\
\text { lo leído? ¿Quién puede decir algo más? Se pide la opinión } \\
\text { acerca de las características positivas o negativas de los } \\
\text { personajes. }\end{array}$ & Papel bond & $5^{\prime}$ \\
\hline & $\begin{array}{l}\text { Se piden que se reúnan en grupo y realicen un dibujo } \\
\text { acerca de algún aspecto de la lectura que lo presenten y } \\
\text { hagan comentarios. }\end{array}$ & $\begin{array}{l}\text { Marcador creyones de } \\
\text { cera }\end{array}$ & $15^{\prime}$ \\
\hline
\end{tabular}

Este taller se puede repetir con diferentes textos, se recomienda al facilitador cambiar la actividad de inicio y el cierre evaluativo además de dibujos puede hacer uso de la construcción de un mapa mental o la elaboración de una composición con recortes, la organización de imágenes de acuerdo al desarrollo del cuento.

Para la evaluación de la actividad el facilitador del taller utilizará la siguiente guía de observación: 
Estudiante: Actividad: Fecha: Lectura:

\begin{tabular}{|c|c|c|c|c|}
\hline No. & Conductas & \multicolumn{2}{|c|}{ Día 1} & Observaciones \\
\hline 1 & Menciona características físicas de los personajes del cuento & $\mathrm{Si}$ & No & \\
\hline 2 & Realiza comentarios sobre los personajes del cuento & & & \\
\hline 3 & Responde a las preguntas relacionadas con el texto & & & \\
\hline
\end{tabular}

Rincón del cuento 1 “Reconociendo a los personajes de un cuento”.

\begin{tabular}{|c|c|c|c|}
\hline Actividad & Descripción & Materiales & Tiempo \\
\hline $\begin{array}{l}\text { Les } \\
\text { presentamos } \\
\text { aaaa.... }\end{array}$ & $\begin{array}{l}\text { Se les presentará a los niños imágenes de dibujos } \\
\text { infantiles clásicos, como ser pato Donald, caperucita } \\
\text { roja entre otros Con base en esos personajes narren } \\
\text { lo que recuerdan de esos cuentos. }\end{array}$ & $\begin{array}{l}\text { Láminas con las fotos de } \\
\text { los personajes }\end{array}$ & $15^{\prime}$ \\
\hline \multirow[t]{2}{*}{$\begin{array}{l}\text { Creando una } \\
\text { lámina }\end{array}$} & $\begin{array}{l}\text { Reunidos en grupo trabajaran para identificar y } \\
\text { pegarlas fotografías de los personajes clásicos que } \\
\text { se les suministren. }\end{array}$ & $\begin{array}{l}\text { Imágenes con las fotos } \\
\text { de los personajes, hojas } \\
\text { de papel y pegamento }\end{array}$ & $20^{\prime}$ \\
\hline & $\begin{array}{l}\text { Crear una historia entre todos con base en las } \\
\text { características de los personajes de las fotografías }\end{array}$ & & \\
\hline
\end{tabular}

Nombre del taller: "La luz de la lectura comprensiva 2"

Objetivo: Reconocer las características positivas o cualidades y las características negativas de los personajes de un cuento a través de una lectura para los niños planificadas y elaboradas por el facilitador con base en tareas y actividades participativas.

\begin{tabular}{|c|c|c|c|}
\hline Etapas & Descripción & Materiales & Tiempo \\
\hline $\begin{array}{l}\text { Presentación } \\
\text { Yoga para } \\
\text { niños }\end{array}$ & $\begin{array}{l}\text { El facilitador pedirá a los niños que realicen una ronda } \\
\text { donde todos imitarán las posturas de algún animal de } \\
\text { su preferencia }\end{array}$ & Ninguno & 5 \\
\hline Diagnóstico & $\begin{array}{l}\text { Se leerá a los niños una historieta de súper } \\
\text { héroes, a partir de la cual identificarán entre todos } \\
\text { a las características positivas y negativas de los } \\
\text { personajes. El facilitador escribirá en la pizarra todo } \\
\text { lo mencionado por los niños en columnas. }\end{array}$ & $\begin{array}{l}\text { Historieta } \\
\text { Pizarrón } \\
\text { Marcador }\end{array}$ & $15^{\prime}$ \\
\hline
\end{tabular}




\begin{tabular}{llll}
\hline \multicolumn{1}{c}{ Etapas } & \multicolumn{1}{c}{ Descripción } & Materiales & Tiempo \\
\hline $\begin{array}{l}\text { Desarrollo } \\
\text { del tema }\end{array}$ & $\begin{array}{l}\text { Se leerá a los niños una poesía breve y de fácil } \\
\text { comprensión, para que el facilitador pida que todos } \\
\text { describan al personaje principal }\end{array}$ & Poesía & 10 min \\
Aplicación & $\begin{array}{l}\text { Se les entregará a los niños una hoja que contenga } \\
\text { un cuento breve se les da instrucciones para que } \\
\text { escriban los aspectos positivos y los negativos de los } \\
\text { personajes. }\end{array}$ & Hoja de evaluación & 15' \\
Evaluación & $\begin{array}{l}\text { Mediante la hoja ya realizada por los niños se } \\
\text { identificará si escribieron las características positivas } \\
\text { y negativas de los personajes del cuento. }\end{array}$ & $\begin{array}{l}\text { Resultados de la hoja de } \\
\text { evaluán }\end{array}$ & \\
\hline
\end{tabular}

\section{Nombre del taller: la luz de la lectura comprensiva 3}

Objetivo: Identificar a los personajes y escenarios de un cuento.

\begin{tabular}{|c|c|c|c|}
\hline Etapas & Descripción & Materiales & Tiempo \\
\hline $\begin{array}{l}\text { Inicio } \\
\text { "Relajando } \\
\text { mi cuerpo" }\end{array}$ & $\begin{array}{l}\text { Se les pedirá a los niños que se acuesten o reclinen } \\
\text { sobre las telas, colchonetas o cojines que el facilitador } \\
\text { colocará sobre el suelo. } \\
\text { Se les dará instrucciones a los niños para realizar } \\
\text { movimientos de estiramiento y relajación. }\end{array}$ & $\begin{array}{l}\text { Telas } \\
\text { Ojines } \\
\text { Colchonetas }\end{array}$ & $5^{\prime}$ \\
\hline Diagnóstico & $\begin{array}{l}\text { Se les presentará a los niños un cuento con secuencia de } \\
\text { imágenes, la cual los niños deberán ordenarla y señalar } \\
\text { todo lo que ven en las imágenes. }\end{array}$ & El libro de cuento & $10^{\prime}$ \\
\hline Desarrollo & $\begin{array}{l}\text { Se les leerá a los niños un cuento que contenga la } \\
\text { descripción de ambientes naturales como: cerros, } \\
\text { cascadas, ríos, mares, animales, plantas, entre otros. } \\
\text { El facilitador realizará pausas durante la lectura y } \\
\text { preguntará a los niños si ellos conocen alguno de estos } \\
\text { ambientes. Les pedirá que lo describan (color, tamaño, } \\
\text { ubicación). }\end{array}$ & Cuento & $10^{\prime}$ \\
\hline Aplicación & $\begin{array}{l}\text { El facilitador llevará a los niños alrededor de la escuela, } \\
\text { y deberán señalar los lugares que se leyeron en el cuento } \\
\text { y anotarlas en su cuaderno, para luego dibujarlos, } \\
\text { colorearlos y pegarlos en el rincón de cuentos. }\end{array}$ & $\begin{array}{l}\text { Lápices } \\
\text { Creyone } \\
\text { Tijers } \\
\text { Pegamento } \\
\text { Cartelera }\end{array}$ & $30^{\prime}$ \\
\hline Evaluación & $\begin{array}{l}\text { El facilitador recoge la información en la guía de } \\
\text { observación }\end{array}$ & Guía de observación & \\
\hline
\end{tabular}


La evaluación se realizará con una guía de observación de conductas.

Estudiante: Fecha: Lectura:

\begin{tabular}{clcc}
\hline No. & \multicolumn{1}{c}{ Conductas } & Día 1 & Observaciones \\
\hline 1 & Elabora la secuencia de un cuento mediante las imágenes & Si & No \\
2 & Señala la relación que tiene el cuento con su entorno & & \\
3 & Responde a las preguntas relacionadas con la lectura & & \\
4 & $\begin{array}{l}\text { Describe diferentes elementos del ambiente o contexto del } \\
\text { cuento }\end{array}$ & \\
\hline
\end{tabular}

\section{Nombre del taller: la luz de la lectura comprensiva 4}

Objetivo: Identificar la secuencia de los hechos ocurridos de un texto leído mediante imágenes.

\begin{tabular}{|c|c|c|c|}
\hline Etapas & Descripción & Materiales & Tiempo \\
\hline $\begin{array}{l}\text { Inicio } \\
\text { "Relajando } \\
\text { mi cuerpo" }\end{array}$ & $\begin{array}{l}\text { Se les pedirá a los niños que se acuesten o reclinen } \\
\text { sobre las telas, colchonetas o cojines que el facilitador } \\
\text { colocará sobre el suelo. } \\
\text { Se les dará instrucciones a los niños para realizar } \\
\text { movimientos de estiramiento y relajación. }\end{array}$ & $\begin{array}{l}\text { Telas } \\
\text { Ojines } \\
\text { Colchonetas }\end{array}$ & $5^{\prime}$ \\
\hline Diagnóstico & $\begin{array}{l}\text { Se les presentará a los niños } 4 \text { cartillas con imágenes, las } \\
\text { cuales siguen una secuencia de una actividad. Los niños } \\
\text { tendrán que ordenarla. }\end{array}$ & Láminas o cartillas & $10^{\prime}$ \\
\hline Desarrollo & $\begin{array}{l}\text { El facilitador realizará una lectura de un cuento, la } \\
\text { lectura la realizaran todos al mismo tiempo, para luego } \\
\text { realizar un análisis del contenido. }\end{array}$ & Cuento & $10^{\prime}$ \\
\hline Aplicación & $\begin{array}{l}\text { Se volverá a presentar a los niños cartillas en un mayor } \\
\text { número, los niños reunidos en grupos ordenan y pegan } \\
\text { la secuencia de la historia en la misma secuencia que la } \\
\text { lectura. }\end{array}$ & $\begin{array}{l}\text { Cartilla } \\
\text { Hilo } \\
\text { Pegamento }\end{array}$ & $30^{\prime}$ \\
\hline Evaluación & $\begin{array}{l}\text { El facilitador recoge la información en la guía de } \\
\text { observación }\end{array}$ & Guía de observación & \\
\hline
\end{tabular}




\section{Rincón Teatral}

Objetivo: Dramatizar la secuencia de un cuento para la identificación de la secuencia de los hechos narrados.

\begin{tabular}{|c|c|c|c|}
\hline Actividad & Descripción & Materiales & Tiempo \\
\hline \multirow[t]{2}{*}{ Actuación } & $\begin{array}{l}\text { Se proporciona a los niños, los guiones de una pequeña } \\
\text { obra de los "tres cerditos y el lobo feroz" y se les repartirá } \\
\text { cada personaje, para que los niños actúen de acuerdo al } \\
\text { personaje, y siguiendo la secuencia del cuento. }\end{array}$ & $\begin{array}{l}\text { Caja de disfraces y, } \\
\text { obra y guiones }\end{array}$ & $30^{\prime}$ \\
\hline & $\begin{array}{l}\text { Anticipadamente se les proporcionará todo tipo } \\
\text { de disfraces para que los niños actúen y creen a su } \\
\text { personaje para la actuación }\end{array}$ & & \\
\hline Evaluación & $\begin{array}{l}\text { El facilitador - psicopedagogo llenará la guía de } \\
\text { observación }\end{array}$ & Guía de observación & Suficiente \\
\hline
\end{tabular}

\section{Rincón del cuento 2}

Objetivo: Practicar la técnica de lectura en voz alta y lectura silenciosa.

\begin{tabular}{|c|c|c|c|}
\hline Actividad & Descripción & Materiales & Tiempo \\
\hline $\begin{array}{l}\text { Leer el texto, } \\
\text { variando la } \\
\text { intensidad de } \\
\text { la voz según } \\
\text { el tamaño de } \\
\text { las letras }\end{array}$ & $\begin{array}{l}\text { Se entrega a cada niño un cuento breve, en el cual la } \\
\text { letra varía de tamaño. } \\
\text { Se explica que si las letras son grandes leerán en voz } \\
\text { alta, si es una letra pequeña leerán en voz baja. }\end{array}$ & $\begin{array}{l}\text { Cuento impreso con } \\
\text { párrafos en diferente } \\
\text { tamaño de letra }\end{array}$ & $20^{\prime}$ \\
\hline $\begin{array}{l}\text { Lectura } \\
\text { silenciosa }\end{array}$ & $\begin{array}{l}\text { Se entrega a cada niño un cuento breve para que lo lean } \\
\text { en silencio. } \\
\text { Realizar preguntas de retención espontánea, retención } \\
\text { guiada y la inferencia. }\end{array}$ & Cuento & $20^{\prime}$ \\
\hline
\end{tabular}

Se les manifiesta a los niños la culminación del taller, se agradece su participación y colaboración. Se pide la opinión acerca de las actividades realizadas, cuáles son sus sensaciones después del taller.

\section{CONCLUSIONES}

La comprensión lectora de la muestra de estudiantes es deficiente.
La comprensión lectora se mide en tres dimensiones de acuerdo al procesamiento de la información contenida en la lectura: (a) recuperación, (b) interpretación y (c) valoración.

Para describir la recuperación de la información se observa si los estudiantes logran identificar el mensaje central, recuerdan frases de la lectura, se adelantan a los acontecimientos de la historia, preguntan acerca de algún aspecto de la lectura y su capacidad para responder preguntas. 
Esta dimensión se caracteriza por las deficiencias para recuperar el mensaje que contiene la lectura, no se reconocen las partes más interesantes o sobresalientes del cuento leído, no muestran interés ni capacidad para responder preguntas.

La recuperación de la información se les facilita un poco, a los estudiantes cuando otra persona lee el texto, se les dificulta cuando son ellos mismos quienes realizan la lectura.

La interpretación de la información mide la capacidad para la elaboración de resúmenes o síntesis y la caracterización de la historia a través de imágenes. En esta dimensión se observan dificultades para interpretar la lectura con base en las imágenes del texto y establecer la relación existente con su entorno. No tienen competencias para hacer comentarios de los personajes o de los lugares contenidos en el texto ni para realizar síntesis o resúmenes y relacionar con el entorno. Sin embargo, al usar láminas y representaciones relacionadas con la lectura mejora un poco la interpretación.

La valoración de la información es muy baja, para esta dimensión se consideran tres indicadores: calificar la posición ante a la lectura, evaluar la actitud de los personajes e identificar características positivas y negativas de los personajes. No se observa la capacidad para que los estudiantes valoren la información de la lectura, no identifican aspectos positivos, negativos, agradables o desagradables.

La comprensión lectora de la población en esta investigación es deficiente.

Con base al diagnóstico de la comprensión lectora se diseña la propuesta de estrategia didáctica para desarrollar la comprensión lectora de los niños de primer grado, fundamentada en los principios de aprendizaje significativo, colaborativo, lúdico.

La propuesta está constituida por actividades creativas, interesantes y divertidas que involucren diferentes acciones de los participantes para desarrollar competencias en la comprensión lectora.

\section{REFERENCIAS}

Baker, S., Smolkowski, K., Katz,R., Fien H.,Seeley, J., Kame'enui, E. y Beck, C. (2008). Reading Fluency as a Predictor of Reading Proficiency in Low Performing High Poverty Schools. School Psychology Review, 37 (1), pp. 18-37 https:// www.tandfonline.com/doi/abs/10.1080/027960 15.2008.12087905

Bravo, L. (2000). Los procesos cognitivos en el aprendizaje de la lectura inicial. Pensamiento Educativo, 27 (2), pp. 49-69

Brunner, J. y Elacqua, G. (2003). Capital humano en Chile. Escuela de Gobierno-Universidad Adolfo Ibáñez, Santiago de Chile

Cabell, S., Justice, L. Konold, T., y McGinty, A. (2011). Profiles of Emergent Literacy Skills among Preschool Children Who are at Risk for Academic Difficulties Early Childhood Research Quarterly, 26, pp. 1-14. https://eric. ed.gov/?id=EJ906811

Cuetos, F. (2008). Psicología de la Lectura. España: Escuela Española.

Defior, S. (1996). Las dificultades de aprendizaje: un enfoque cognoscitivo. Málaga: AJIBE

Di Scala, M. y Cantú, G. (2011). Diagnóstico psicopedagógico en lectura y escritura. Test DIP(le) (8 ${ }^{\mathrm{a}}$ ed.). Buenos Aires - México: Novedades Educativas

Diaz Barriga, F y Hernández. G. (2002) Estrategias para el aprendizaje significativo. Una interpretación constructivista. México: McGraw Hill

Gervilla, A. (2006). Didáctica básica de la Educación Infantil. España: Narcea

González, T. (2005). Comprensión lectora en niños morfosintaxis y prosodia en acción. Granada: Universidad de Granada

López, R. (2014). Concepciones sobre la lectura y la escritura y su implicación en las prácticas de enseñanza inicial. Pedagogía Infantil, 6-59

Martínez, T., Vidal-Abarca, E., Sellés, P., \& Gilabert, R. (2008). Evaluación de las estrategias y procesos de comprensión: el Test de Procesos de Comprensión. Infancia y Aprendizaje, 31(3), 319 - 332 
Medina, A. (2006).Enseñar a leer y escribir: ¿en qué conceptos fundamentar las prácticas docentes? Psykhe, 15 (2) (2006), pp. 45-55

Navarro, J. (2005). Estrategias de Comprensión Lectora. Argentina: Lumen

Niño, V. (2010). Competencias de la comunicación hacia las prácticas del discurso. Bogotá: Eco ediciones
Parodi, G. (2010). Saber leer. Buenos Aires: Aguilar e Instituto Cervantes

Paymal, N. (2008). Pedagogía 3000. Córdoba: Brujas 